\title{
Cooperative Analysis of a Standard Sample of Natural Gas with the Mass Spectrometer
}

\author{
By Martin Shepherd ${ }^{1}$
}

\begin{abstract}
The mass spectrometer was used for the analysis of a standard sample of natural gas by laboratories cooperating with Subcommittee VII of Committee D-3 of the American Society for Testing Materials. The results of the cooperative analysis show the reproducibility and, in certain respects, the accuracy of this powerful new apparatus for gas analysis. The heating value and the specific gravity of the sample calculated from the analytical data were compared with the known values.
\end{abstract}

\section{Introduction}

This report is the third of a series of cooperative analyses of standard gas samples ${ }^{2}$ conducted to furnish basic information for the preparation of standard methods for the analysis of fuel gases. The development of these standards is a task assigned to Subcommittee D-3-VII of the ASTM, and the method of this development has been outlined in two previous reports. ${ }^{3}$

The 20 laboratories that cooperated in the present work were widely distributed geographically, but most of them were associated with the petroleum industry. There was some representation from the chemical industry, but only one college and one Federal bureau participated. Fortunately, both of the companies making the spectrometers used in this series of analyses contributed the services of the instruments in their home laboratories. The cooperating laboratories owned 21 mass spectrometers. Of these, 18 were manufactured by the Consolidated Engineering Corporation and the other three by the Westinghouse Electric Corporation. The Consolidated

\footnotetext{
${ }^{1}$ Chairman of Subcommittee VII (Analysis of Gaseous Fuels) of Com mittee D-3 (Gaseous Fuels), American Society for Testing Materials.

2 These samples are not to be confused with the regular standard samples prepared and offered for sale by the National Bureau of Standards. They are mixtures prepared especially for these cooperative analyses and are issued to laboratories cooperating with the American Society for Testing Materials on this project.

${ }^{3}$ Martin Shepherd, Analysis of a standard sample of the carburetted watergas type by laboratories cooperating with the American Society for Testing Materials, J. Research NBS 36, 313 (1946) RP1704; Analysis of a standard sample of natural gas by laboratories cooperating with the American Society for Testing Materials, J. Research NBS 38, 19 (1947) RP1759.
}

spectrometer ${ }^{4}$ operates with a fixed magnetic field and varying accelerating voltage; the Westinghouse spectrometer ${ }^{5}$ reverses this system. The Consolidated instrument produces its spectrogram photographically with a recording oscillograph; the Westinghouse instrument employs a pen-and-ink recorder. However, the basic principle upon which each was built is the same, and the analytical results should be the same. Indeed, it will be observed that results from the two instruments are not widely different, although there were some definite suggestions of individuality. In both types of instruments there were minor variations in design. Two different models of the Consolidated instrument operated with different rates of scan, somewhat different sensitivity, and a slight difference in the system for focusing the ion beam-apparently with no significant difference in the analytical results. The Westinghouse instruments were equipped with linear or log-linear recorders, and one of the three was a laboratory research model, not a production model.

The same freedom from variety noted for the apparatus was true also for the analytical procedures. In general, all of the laboratories followed the procedures for operating, calibrating, and computing prescribed by the manufacturers.

\footnotetext{
${ }^{4}$ H. W. Washburn, H. F. Wiley, S. M. Rock, and C. E. Berry, Mass spectrometry, Ind. Eng. Chem. Anal. Ed. 17, 74 to 81 (1945), and manuals issued by the Consolidated Engineering Corporation to users.

${ }^{5}$ J. A. Hipple, Gas analysis with the mass spectrometer, J. Applied Phys. 13, 551 (1942), and manusls issued by the Westinghouse Electric Corporation to users.
} 
Departures from the prescribed course were very few and of such a nature that no significant change was expected or observed. Perhaps the greatest variation was in the calibrating substances used, some of which were obtained from different sources and were not of uniform purity.

Thus, with respect to both apparatus and methods, this series of cooperative analyses was accorded the convenience of standardization which was unofficial but none the less real; and while this may or may not have been a factor in the accuracy achieved, it must have affected the over-all reproducibility.

\section{Standard Natural Gas Sample ASTM D-3-VII-3}

The preparation of the standard sample of the natural-gas type, identified as ASTM D-3-VII-2, which was used in the cooperative analysis by volumetric chemical methods, has been described in detail in Bureau Research Paper RP1759. ${ }^{6}$ The account given in RP1759 will serve to establish the complete history of the present sample, ASTM D-3-VII-3, which was analyzed by the mass spectrometer - as the No. 2 and No. 3 samples were identical. This was not disclosed when No. 3 was issued, and accordingly it was analyzed as a blind sample. In general, it did not find its way into the same laboratories that had performed the chemical analyses. In a few cases, however, the results obtained by the mass spectrometer came under the same reviewing eye as had those obtained by the chemical methods. How many positive correlations were made is not known. In only one case was a puzzled suspicion voiced.

Sample ASTM D-3-VII-3 was issued in the same type of cylinder as that used for the No. 2 sample, and the instructions for transferring it to the spectrometer without contamination were essentially the same as those given for the previous sample (see RP1759). This information will accordingly not be repeated here.

Having thus put chemical and physical methods into direct competition, it is of considerable interest to see what happened. The part of the story concerned with the analysis by the mass spectrometer is given in this paper. (An addi-

${ }^{6}$ See footnote 3 . tional report comparing the chemical and physical analysis is in preparation.)

\section{Analytical Results}

All of the analytical data submitted have been tabulated, together with the average values derived from each laboratory series; but the contemplation of these data for a considerable time would not serve to reveal what may be seen at a glance when these same data are presented in a series of frequency-distribution plots. Accordingly, these plots, which amount to actual pictures of the analytical results, have been chosen as the best method of presentation and what few remarks seem justified have been included in the legends of the corresponding plots.

In the plots each circle represents a value derived from a single determination of the substance whose name appears in the legend. The circles are plotted equidistant on the ordinate corresponding to their values. Thus, the abscissas are values derived from the analyses, and the ordinates indicate the frequency with which these values occur. For example, the lower section of the frequency-distribution plot for methane (fig. 1) shows that one determination gave the value 75.4 percent, two determinations gave 75.5 percent, one gave 76.0 percent, one gave 76.4 , four gave 76.7 , eight gave 76.8 , and so on. The lower section of this plot is marked $\mathrm{C}+\mathrm{W}$, and shows all of the 118 determinations of methane made with both the Consolidated and Westinghouse instruments. In the middle section, marked $\mathrm{W}$, the Westinghouse results are separately plotted. The top section shows the averages from each of the laboratories (or perhaps more properly, from each of the instruments, since there were 20 laboratories and 21 instruments). In this section the $\mathrm{W}$ values are indicated with open circles.

These conventions are carried throughout the group of plots. In some cases, where relatively few determinations of a component (often actually not in the sample) have been reported, division of the plot into three sections has not been necessary, for there are neither $W$ values nor laboratory averages. With these conventions in mind, the frequency-distribution plots can be studied. 

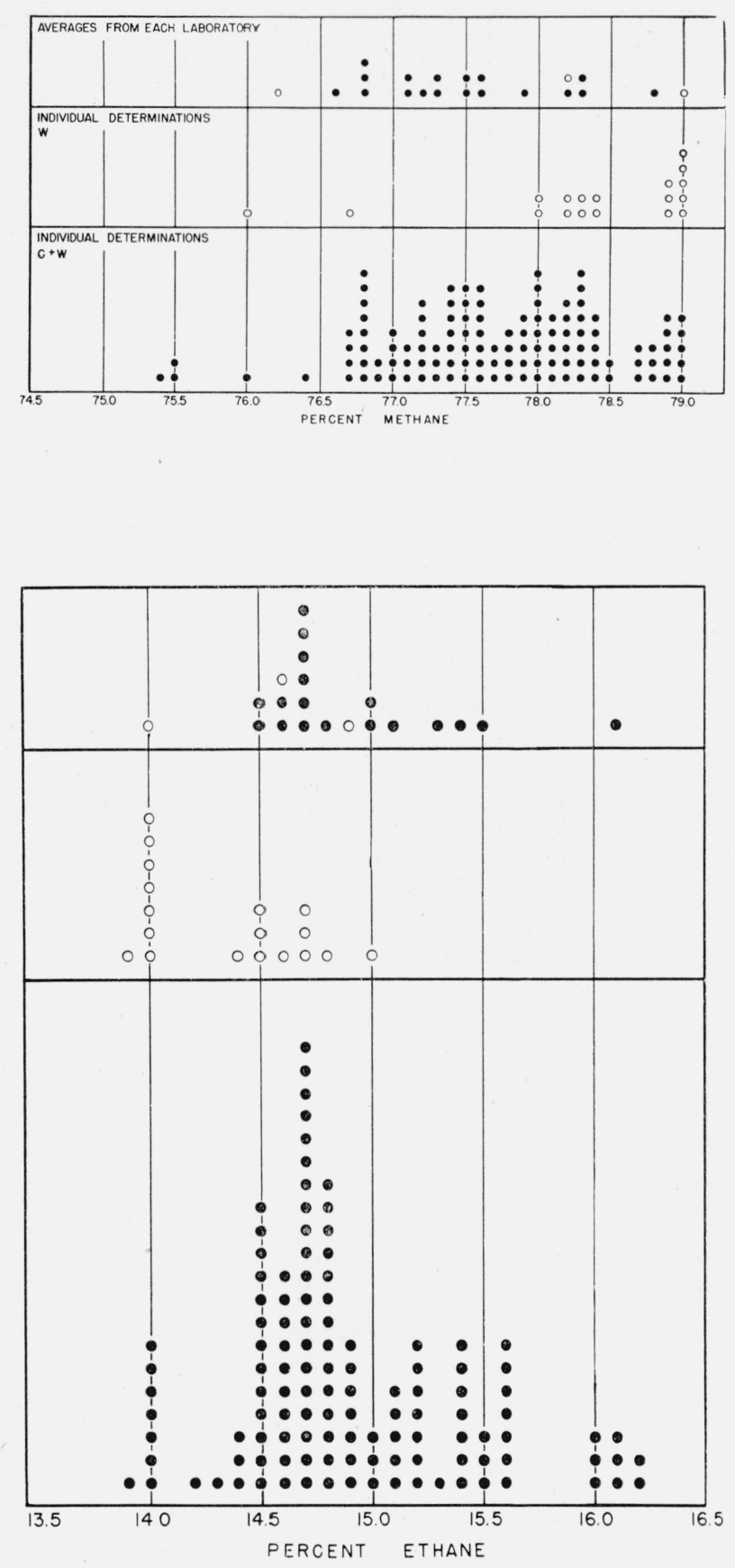

Figure 1.-Frequency-distribution plot for methane.

All determinations are given in the lower section $(\mathrm{C}+\mathrm{W})$, and those made by the $\mathrm{W}$ instruments are given separately in the middle section (W). The upper section shows the averages from each of the laboratories. The analyses yielded values over a range of 4.6 percent, although 80 percent of the determinations were confined to a range of 1.8 percent. Within this lesser range, the distribution is fairly even, with no tendency to a greater frequency at any value, and with an arithmetical mean of $77.6 \pm 0.5$. The mean of the whole group is 77.7 , and that of the laboratory averages is $77.5 \pm 0.6$. Outside values appear in both the $\mathrm{W}$ and $\mathrm{C}$ determinations. The \pm values noted indicate reproducibility expressed as the average absolute deviation from the average given.
FiguRE 2.-Frequency-distribution plot for ethane.

The three sections of the plot follow the same convention used in the plot for methane. The analyses yielded values ranging over 2.3 percent, with a mean value of 14.9. The greatest frequency appears at 14.7 percent. Eighty percent of the determinations are confined within a range of 1.1 percent; the mean of this group is $14.9 \pm 0.3$. The mean of the laboratory averages, exclusive of the two outside values, is $14.8 \pm 0.2$. Some of the $W$ values are not in agreement with the general group. 


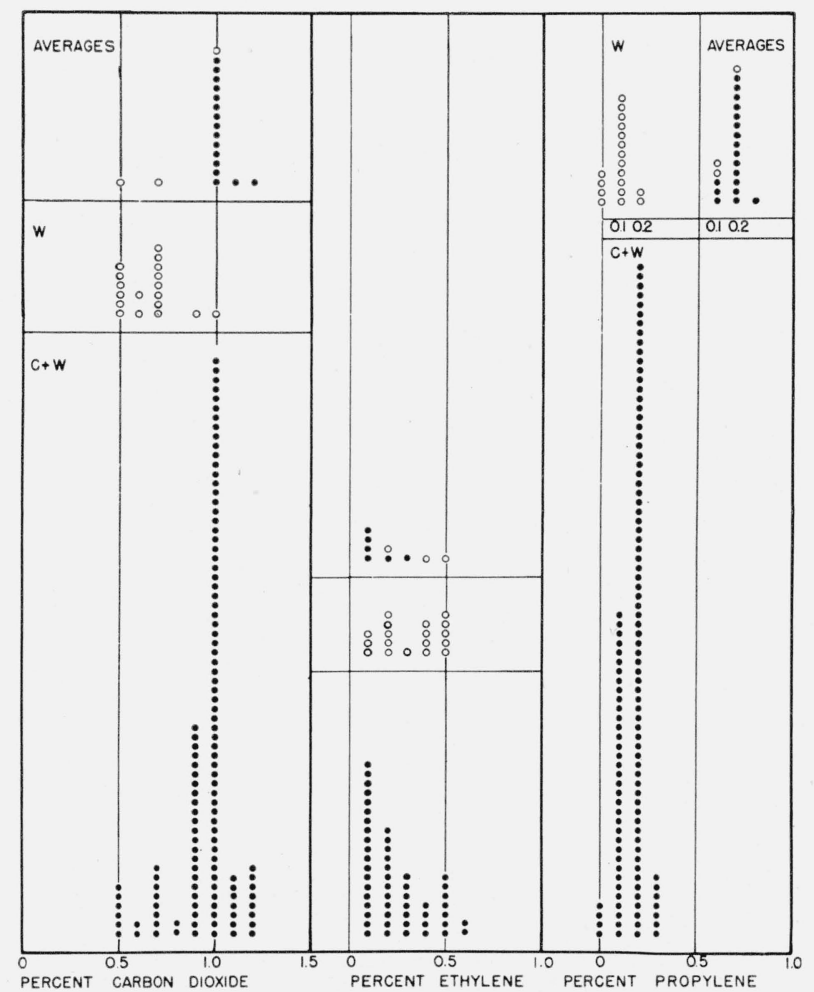

Figure 3.-Frequency-distribution plots for carbon dioxide, ethylene, and propylene

Carbon dioxide.-The greatest frequency appears at 1.0 percent. The arithmetical mean of the whole group is 0.94 ; but with the low W values excluded, the mean is 1.00 . The most probable value, based on determinations within 0.1 percent of the value of greatest frequency, is $1.00 \pm 0.03$ percent. Volumetric chemical analysis in an all-glass apparatus gave the value $1.00 \pm 0.02$ percent

Ethylene.-Was reported in nearly half of the analyses - 51 out of 118 determinations - and by 10 of the 21 instrument-laboratory combinations. The greatest frequency appears at 0.1 percent, and the mean of all plotted values is 0.26 percent. All three of the $\mathrm{W}$ instruments reported this hydrocarbon; $\mathrm{C}$ instruments were not so unanimous, although 7 of the 18 indicated its presence. The uncertainty of opinion as to whether or not ethylene was present -43 percent for and 57 percent against-is interesting. There was no such uncertainty concerning propylene. In this connection, there was no positive correlation between low propylene and the presence of ethylene.

Propylene.-Although only about half of the analyses appeared to separate ethylene as a constituent of this sample, the identification of propylene was almost unanimous. Propylene was reported in 114 of 118 determinations, with the greatest frequency at 0.2 , a mean of $0.2 \pm 0.04$, and a mean of $0.2 \pm 0.03$ for the laboratory averages. $W$ instruments tend to the value 0.1 rather than 0.2 . The total spread, 0 to 0.3 percent, and the high frequency at 0.2 percent attest the remarkable resolving power of the mass spectrometer in this instance. Special chemical analysis gave the result $0.19 \pm 0.04$ as the total amount of $\mathrm{C}_{n} \mathrm{H}_{2 n}$ in this sample.
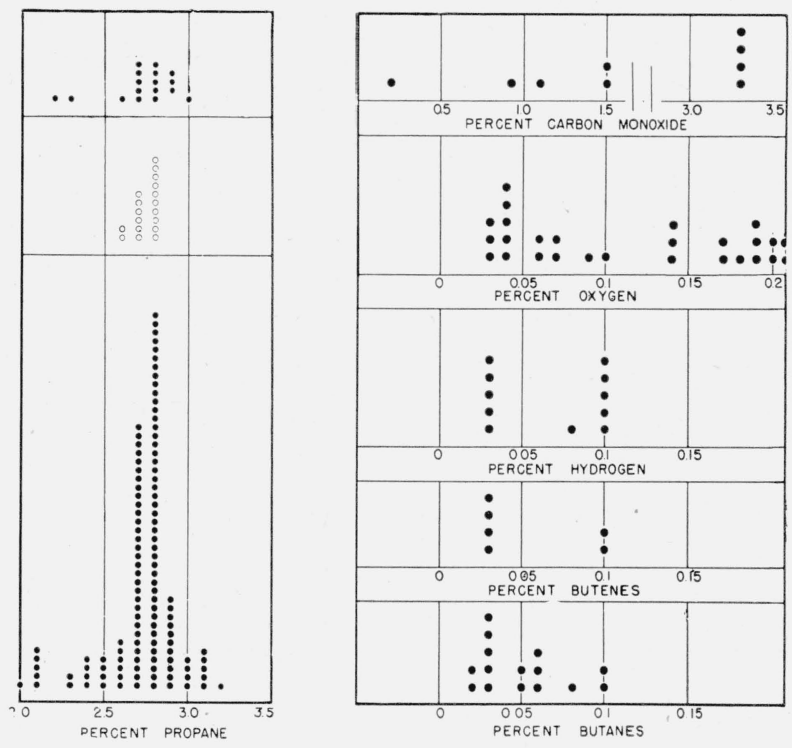

Figure 4.-Frequency-distribution plots for propane and for various gases not in the sample.

Propane.-These values spread over a range of only 1.2 percent, with a mean value of 2.7. Seventy-eight percent of the determination lie within 0.4 percent, with a mean value of $2.8 \pm 0.06$. The greatest frequency is at 2.8 percent. The $\mathrm{W}$ values are well within the general group. The mean of the laboratory averages, excluding the two low values, is $2.8 \pm 0.1$.

Carbon monoxide.-Only 9 of the 118 analyses "discovered" carbon monoxide. The distribution was random, and it is quite evident that $\mathrm{N}_{2}$ and $\mathrm{CO}$ have been confused in some of the reported instances. There was no CO in this sample. NBS colorimetric indicating tubes were used to prove this fact. (Martin Shepherd, A preliminary report on the NBS colorimetric indicating gel for the rapid determination of small amounts of carbon monoxide, Anal. Chem. 19, 77 (1947)).

Oxygen.--Reported in 27 out of 118 determinations (23 percent of the samples examined). The distribution was random. Smaller amounts may not have been significant, and larger amounts represented contamination with air, probably in transferring the sample to the spectrometer. The sample itself contained no oxygen.

Hydrogen.-Found in 11 of the 118 analyses, always in small amounts and with random distribution. There was no hydrogen in the sample. Its absence was established (within \pm 0.001 percent) by separation at the temperature of liquid hydrogen, using the apparatus and methods described in Bureau Research Paper RP75.

Butenes.-Only 6 of 118 determinations indicate the presence of butenes in small amounts ( 0.03 to 0.1 percent). It is very doubtful if butenes were present in this sample.

Butanes.-Reported in 15 of 118 determinations, in small amounts ranging from 0.02 to 0.1 percent, and with random distribution. It is possible that the sample may have contained about 0.05 percent of $n$ +isobutane, but this is not certain. One laboratory analyzed a fraction of this sample condensed at low temperature, thus increasing the relative proportion of $\mathrm{C}_{4}$ hydrocarbon if present. $\mathrm{No}_{4}$ component was identified.

The three Westinghouse instruments did not report $\mathrm{CO}, \mathrm{H}_{2}, \mathrm{O}_{2}$, or $\mathrm{C}_{4}$ hydrocarbons. 

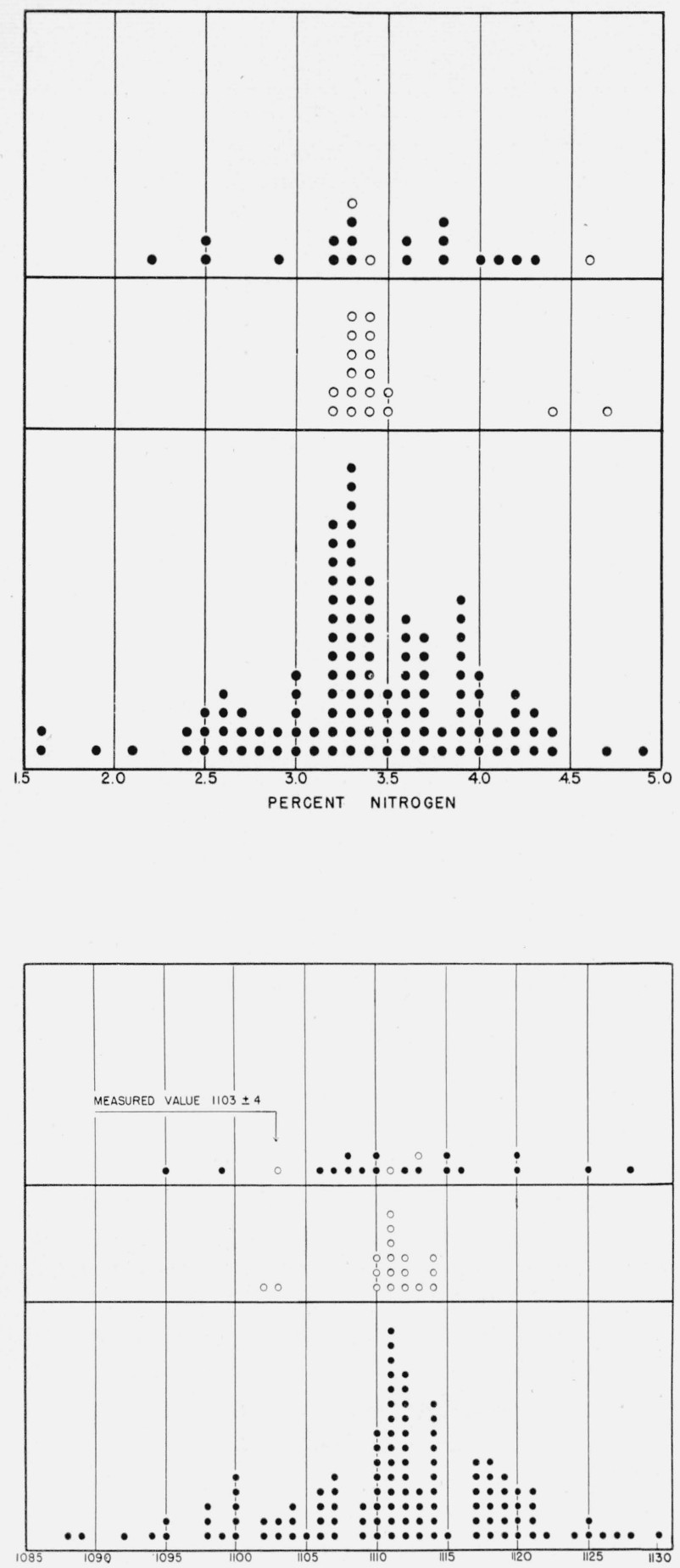

BTU PER CUBIC FOOT
FiguRe 5.-Frequency-distribution plot for nitrogen.

Results for nitrogen are somewhat scattered over a range of 3.3 percent, with the greatest frequency at 3.4 percent. This casts some doubt upon the composition of the mixture with respect to this component. The mean of all determinations is 3.4 , while the mean of values from 3.0 to 4.0 percent inclusive, representing 71 percent of the whole group, is $3.5 \pm 0.3$. The laboratory averages ranged from 2.2 to 4.6 percent, with a mean of $3.5 \pm 0.5$. Nitrogen was reported in 114 of the 118 determinations, but in four cases, nitrogen was identified as carbon monoxide. The $\mathrm{W}$ values are generally consistent with the best values to be derived. Volumetric ehemical analysis in all-glass apparatus with direct measurement of residual inert gas gave the value $3.5 \pm 0.1$ percent for this sample.

FiguRE 6.-Frequency-distribution plot for the calculated heating value.

The measured heating value of this sample was $1,103 \pm 4 \mathrm{Btu} / \mathrm{ft}^{3}$ (measurements were made with the Junker's calorimeter by J. H. Eiseman and R. Jessup of the National Bureau of Standards. This value was originally reported as 1,103 in RP1759, but the procedures for calculation as given in the new ASTM Tentative Method of Test for the Calorific Value of Gaseous Fuels by the Water-Flow Calorimeter, ASTM Designation D900-46T, shifts the value to $\left.1,105 \mathrm{Btu} / \mathrm{ft}^{3}\right)$. The values calculated from anaryses by the mass spectrometer are generally higher than the measured value and extend over $42 \mathrm{Btu} / \mathrm{ft}^{3}$. The highest frequency appears at $1,111 \mathrm{Btu} / \mathrm{ft}^{3}$. The mean of all values is 1,111 . The mean of values from 1,100 to 1,121 , inclusire (about 85 percent of all determinations) is $1,112 \pm 4.4$. The mean of the laboratory averages is $1,111 \pm 6$. The $\mathrm{W}$ values are consistent with the more gregarious of the group. Values derived from the spectrometric analyses are thus higher than the measured value. 


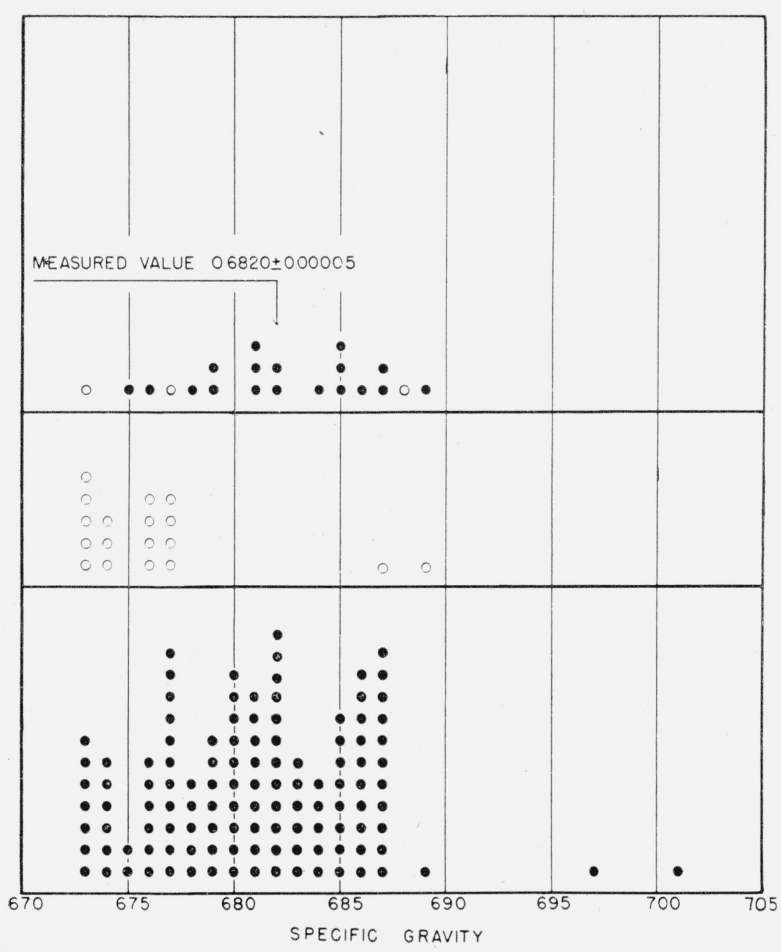

Before laying aside the frequency-distribution plots, a few high lights may be reviewed.

In dealing with about 77 percent of methane in a sample of natural gas, when relatively few determinations are made with one spectrometer selected at random, it is obviously not sensible to think in terms of tenths of a percent when the results obtained by the single spectrometer are to be compared with those of another selected at random. Such amounts may as well be reported to the nearest whole percent. Nearly the same can be said regarding amounts of ethane near 15 percent. However, propane in amounts around 3 percent can conscientiously be reported to the nearest tenth percent; and propylene present to the extent of 0.2 percent can probably be estimated to hundredths of a percent. But while 3 percent of propane can be reported to the nearest tenth percent, 3 percent of nitrogen cannot. Thus, a simple arithmetical convention for rounding out values, which is based only on the order of magnitude of the value, is not dependable.

The astonishing ability to detect and estimate properly 0.2 percent of propylene has been noted. But it is also evident that the mass spectrometer,
FigURE 7.-Frequency-distribution plot for the calculated specific gravity.

The measured specific gravity of this sample was $0.6820 \pm 0.00005$ (Made by Carroll Creitz. For details of this measurement, see NBS Miscellaneous Publication M177, "Tests of instruments for the determination, indication, or recording of the specific gravities of gases"). The specific gravity calculated from the analyses by the mass spectrometer spreads from 0.673 to 0.701 ; but if the three high values are excluded, this range is narrowed to a spread of 0.114 . The results are evenly distributed with no apparent peak, and the group seems slightly lower than the true value. The mean of the group (three high values again eliminated) is $0.681 \pm 0.004$. Thus, while the maximum deviation from the known value is 1.3 percent of this value, the average deviation is 0.6 percent. The $\mathrm{W}$ values are mostly lower than the known value. The mean of the laboratory averages is $0.682 \pm 0.004$. The mean values are in excellent agreement with the known value. with its great sensitivity for small amounts of many gases, is not infrequently capable of detecting gases actually not in the sample under exam. ination. There are some who stoutly maintain that this is no fault of the spectrometers; but obviously it is no virtue.

Although some of the plots show a fairly wide distribution of values, in general, this horizontal displacement illustrating poor reproducibility is not so great here as for the corresponding chemical determinations previously reported. ${ }^{7}$ By comparison, some of the chemical determinations were inconveniently various. The Westinghouse instruments did show some individuality - enough to cause speculation as to what would have happened had there been as many kinds of mass spectrometers and ways of using them as there were kinds of the volumetric chemical apparatus and ways of using them. The present nearstandardization of gas analysis by the mass spectrometer should be incorporated in a tentative standard before it is too late.

The plots have not shown the reproducibility achieved between different computers working

See footnote 3 . 
with the same spectrogram, and between different spectrograms of this sample obtained on the same spectrometer. The reports disclose almost exact agreement in most cases between two computers picking, interpreting, and computing the same spectrogram. Disagreements did not exceed 0.1 percent for the components present in largest amounts. On the other hand, two spectrograms taken with the same spectrometer usually differed by amounts ranging from 0.1 to 0.8 percent. Disagreements of 0.4 or 0.5 were fairly frequent, and agreement to 0.1 was usually not achieved. Apparently checks or 0.2 to 0.3 percent represented the average best work. But it should be remembered that these variations represent the work of a single laboratory, and do not represent the variations among all of the laboratories.

Finally, the most probable composition as determined by all of the mass spectrometers can be set down:

\begin{tabular}{|c|c|}
\hline Component & $\begin{array}{c}\text { Perent } \\
\text { (mole or } \\
\text { volume) }\end{array}$ \\
\hline Methane _.... & 77.6 \\
Ethane__... & $14.9 ?$ \\
Nitrogen_.... & 3.4 \\
Propylene_... & 0.2 \\
Propane__... & 2.8 \\
Carbon diox- & 1.0 \\
ide. & \\
\hline
\end{tabular}

These values correspond to the arithmetical means noted in the legends of the figures. They also represent the medians in every case but that of ethane, where the median is 14.7. Four of the six means were weighted after inspection of the frequency-distribution plot, which indicate how rogues may be weeded out. Unfortunately, this process usually involves some personal judgment and is questionable in direct proportion to the judgment invoked.

In the present instance, the argument is as follows: (1) In case of methane and ethane, one of the $W$ instruments yielded a consistently high methane and a low ethane. This pattern strongly suggests a systematic error (for which an explanation is already at hand). Other values discarded were obviously away from the main block of determinations. Ethane remains in question, since the mode and median are 0.2 percent lower than the mean of all values or the weighted mean, while the weighted mean and the median agree for methane, and are only 0.1 percent lower than the mean of all values. (2) In the case of nitrogen, the mode is 0.1 percent lower than the weighted mean, unweighted mean, and median, all three of which are in agreement. (3) The mode, median, and unweighted mean for propylene are all in agreement, and no need for a weighted mean is evident. (4) The values from 2.6 to 2.9 , inclusive, have been selected in the ease of propane for the weighted mean, which is 0.1 percent higher than the mean for all values - a difference obtained by including obvious rogues around 2 percent in the mean for all determinations. Median and mode agree with the selected mean. (5) In weighing the values for carbon dioxide the mode was strongly influential, as was the knowledge derived from many chemical determinations of this component in the same sample. The chemical mode and mean, and the spectrometric mode, medián, and weighted mean are all in agreement. The preponderance of low values in the W group suggests a systematic error.

\section{Calibrating Gases and Times of Calibration as Affecting Accuracy}

The following observations should be qualified immediately by stating that the term "accuracy" is not used in its strictest sense, but is taken for the moment to mean agreement with the most probable values determined by all the spectrometers, which were noted in the foregoing section. It is known that inaccuracies occured when components known to be absent were reported. The real composition of the sample with respect to nitrogen (more strictly, inert), carbon dioxide, and propylene is closely known. The composition with respect to methane, ethane, and propane can be estimated rather well, but is not known to an order of magnitude better than the analy tical resolution of the mass spectrometer. With these qualifications in mind, the facts concerning calibrating gases and time of calibration may be considered.

There were a number of sources of calibrating gases. In general, the hydrocarbons came from Phillips Petroleum Co., Ohio Chemical \& Manufacturing Co., Matheson Chemical Co. and the Southern California Gas Co. The stated purity 
of the various gases ranged from 98 to $99+$ percent. Nitrogen and oxygen were derived from the commercial compressed gases, or the calibration was made with air. Carbon dioxide was obtained by the sublimation of the solid or from a cylinder of the liquid. Occasionally some of these gases were purified by distillation or prepared at home by the laboratory that used them for the calibrations. These cases were exceptional, and in only one instance was the entire list of calibrating gases given this especial treatment by a laboratory obviously not inclined to take chances. Since there was but this single case, it may not be worth noting that this laboratory reported results which in all cases checked the most probable or the known values to 0.1 percent or closer, a record not equaled elsewhere.

It might be expected that the apparent lack of strict standardization of calibrating gases would be a significant factor affecting accuracy, and indeed this may have been true. But aside from the case just cited, there is no direct evidence of this. There is no correlation between the source of calibrating gas and the amount or direction of the deviation from probable or known values. The correlation in the exceptional case may have as its real basis, not the purity of calibrating substances, but the fact that an operator who insisted upon very unusual care in the preparation of pure calibrating gases would be more than likely to exercise very unusual care in the subsequent analyses.

It might further be expected that more reliance could be placed upon analyses that were computed with calibrating patterns obtained at the same time as the pattern of the unknown. This assumption remains reasonable, even though the reports again failed to show a definite correlation between accuracy and the relative time of calibration and analysis. In a majority of the cases, the calibration patterns were obtained within a week of the patterns for the unknown sample.
In many cases, calibration and analysis were made within 24 hours of one another. But there were enough calibrations made 1,2 , or even 3 months preceding the analysis to show any tendency toward loss of accuracy from this cause - and no such tendency appeared in the data submitted. The conclusion is that, for the present, other factors are more important. But this conclusion does not justify failure to calibrate as often as one desires to know what really goes on. Certainly too little is known about these matters, and until more information is available and the proper requirements are finally developed, it seems reasonable to proceed with greater care than may be necessary.

\section{Conclusions}

The particular needs are a better reproducibility for methane, ethane, and nitrogen, and less enthusiasm in the matter of reporting components actually not present. The tendency toward toohigh calculated heating values suggests an imbalance between the lighter and heavier hydrocarbons. But in general the reproducibility attained was better than that of the chemical methods. One reason for this would appear to be a fair degree of standardization which exists because the method is new and has not yet been subject to great variation of apparatus and procedure. Somehow, the advantage of this standardization should be captured. An ASTM standard is planned as one means of doing this.

Jean Doyle and Marthada Vaughn Kilday checked the calculations of heating value and specific gravity, and this assistance is gratefully acknowledged. Churchill Eisenhart and Celia Martin of the Bureau's Statistical Engineering Section corrected errors in the frequency-distribution plots.

Washington, March 12, 1947. 